\title{
Kinetics of 1-Hexanol Etherification on Amberlyst 70
}

\author{
R. Bringué*, E. Ramírez, M. Iborra, J. Tejero, F. Cunill
}

Chemical Engineering Department, Faculty of Chemistry, University of Barcelona, C/ Martí i Franquès 1-11 08028, Barcelona, Spain

${ }^{*}$ Corresponding author: tel.: +34 934020155, fax: +34 934021291, e-mail address: rogerbringue@ub.edu

\begin{abstract}
The kinetics of the liquid-phase etherification of 1-hexanol to di-n-ethyl ether and water on the ion-exchange resin Amberlyst 70 in the temperature range 423-463K is studied. The strong inhibition effect of water is considered following two approaches. First, a model stemming from a Langmuir- Hinshelwood-Hougen-Watson (LHHW) mechanism was used, wherein the inhibitor effect of water was explained by the competitive adsorption of water and hexanol. Secondly, a modified Eley-Rideal (ER) model that includes an inhibition factor, in which a Freundlich-like function is used to explain the inhibitor effect of water by blocking the access of hexanol to the active centers. Both models fitted data quite well, although the best fitting results were obtained with the modified ER model. The activation energy was $125 \pm 3 \mathrm{~kJ} / \mathrm{mol}$ for the LHHW model and $121 \pm 3 \mathrm{~kJ} / \mathrm{mol}$ for the modified ER one.
\end{abstract}

Keywords: di-n-hexyl ether, 1-hexanol, Amberlyst 70, kinetics, effect of water.

\section{Introduction}

Langmuir-Hinshelwood-Hougen-Watson (LHHW) or its related Eley-Rideal (ER) kinetic models are widely used to represent data of liquid-phase reactions catalyzed by 
solids [1-7] but some inaccuracies appear because of the reaction medium-catalyst interaction. Frequently, some reactant or reaction product adsorbs preferably on the catalyst surface, e.g., polar species onto sulfonic styrene/divinylbenzene (S/DVB) resins, leading to a decrease of the reaction rate. This rate-inhibiting effect of polar species on S/DVB resins is sometimes used to control selectivity to intermediate products in series reactions [8-11], however this effect is undesirable when such polar species, in particular water, are reaction products [12-22]. To quantify the effect of reaction medium-catalyst interaction, empirical corrections are suggested in the open literature. Water effect has been represented by using empirical exponents in the driving force and the adsorption term of LHHW or ER rate-expressions $[12,16]$. In the particular case of liquid-phase etherification reactions, a second approach is found: water effect on the reaction rate is quantified by splitting off the rate constant, $\hat{k}$, into two factors as a product of the true rate constant, $\hat{k}_{o}$, and an inhibition factor, which should take values between 0 and 1 and depends on temperature and water activity, $a_{w}$, in the liquid-phase. Such factor is analogous to those mostly used to describe catalyst deactivation by poisoning and, at first sight, it can be seen as the fraction of active centers free of water $[20-22],\left(1-\theta_{w}\right)$, i.e.,

$$
\hat{k}=\hat{k}_{o} \cdot f\left(a_{w}, T\right)=\hat{k}_{o}\left(1-\theta_{w}\right)
$$

In a previous work [23], the feasibility of the dehydration of 1-hexanol to di-n-hexyl ether (DNHE) on some acidic thermally stable catalysts was proved in the temperature range $423-463 \mathrm{~K}$. Under these conditions, the main reaction was found to be the bimolecular dehydration of 1-hexanol to di-n-hexyl ether and water. 1-hexanol can also undergo dehydration to $\mathrm{C}_{6}$ alkenes, which could hydrate to 2-hexanol (although it was detected in very low amounts). Some branched ether were also detected, which could be produced by the reaction of 1/2-hexanol and a $\mathrm{C}_{6}$ alkene, or bimolecular dehydration of 
2-hexanol. More detailed information about the reaction scheme can be found elsewhere [23]. Among the catalysts tested, the ion-exchange resin Amberlyst 70 was highlighted due to its best behavior at lower temperatures. Moreover, the equilibrium constants for the liquid-phase dehydration of 1-hexanol to DNHE were determined experimentally [24].

The aim of this work is to perform a comprehensive kinetic analysis of DNHE synthesis on Amberlyst 70 in the temperature range 423-463K, taking into account the abovementioned work [23] and new rate data obtained in the presence of additional water and ether amounts in order to stress the effect of water on the kinetic equation.

\section{Materials and methods}

\subsection{Materials}

1-hexanol (99.5\% pure, $<0.3 \%$ 2-methyl-1-pentanol, $0.1 \%$ water) was used after purification in a distillation column of the alcohol supplied by Fluka ( $\geq 98 \%)$. Di- $n$ hexyl ether was obtained in our lab and purified to $\geq 98 \%$. 1-hexene $(\geq 99 \%)$ from Aldrich, trans-2-hexene ( $\geq 98 \%)$, cis-2-hexene ( $\geq 95 \%)$, trans-3-hexene ( $\geq 97 \%)$, cis-3hexene ( $\geq 95 \%)$, and 2-methyl-1-pentanol ( $\geq 99 \%)$ were supplied by Fluka and used for analysis purposes.

The catalyst was the thermally stable acidic resin Amberlyst 70 (A-70), a chlorinated low crosslinked polystyrene-divinylbenzene (PS-DVB) copolymer from Rohm and Haas France. Amberlyst 70 has an acidic capacity of $2.65 \mathrm{meq} \mathrm{H}^{+} / \mathrm{g}$, a skeletal density of $1.52 \mathrm{~g} / \mathrm{cm}^{3}$, mean bead diameter of $0.57 \mathrm{~mm}$, and its maximum operating temperature is $473 \mathrm{~K}$. Some structural properties can be found elsewhere [25].

\subsection{Experimental set-up}


Experiments were carried out in a 100-mL stainless steel autoclave which operates in batch mode. A magnetic drive turbine was the mixing system. Temperature was controlled to within $\pm 1 \mathrm{~K}$ by an electric furnace. To carry out the reaction in the liquid phase pressure was set at 2.1 MPa using $\mathrm{N}_{2}$ as inert gas. One of the outlets of the reactor was connected directly to the liquid sampling valve, which injected $0.2 \mu \mathrm{l}$ of pressurized liquid into a GLC apparatus. More information about the experimental setup can be found elsewhere [26].

\subsection{Analysis}

The composition of liquid mixtures was analyzed by using a split-mode operation in a HP6890A GLC apparatus equipped with TCD, because of the presence of water as a reaction product. A $50 \mathrm{~m} \times 0.2 \mathrm{~mm} \times 0.5 \mu \mathrm{m}$ methyl silicone capillary column was used to determine 1-hexanol, DNHE and by-products: $\mathrm{C}_{6}$ olefins (1-hexene, 2-hexene and 3hexene) and branched ethers (2-hexoxy-2-hexane and 2-hexoxy-1-hexane). The column was temperature programmed with a 6 min initial hold at $318 \mathrm{~K}$, followed by a $30 \mathrm{~K} / \mathrm{min}$ ramp up to $453 \mathrm{~K}$ and holding for $5 \mathrm{~min}$. Helium was used as a carrier gas at a total flow rate of $30 \mathrm{ml} / \mathrm{min}$. Under these conditions the peaks of the chromatogram were clearly defined and isolated, which permitted the separation and identification of all the above mentioned species.

\subsection{Methodology}

Amberlyst 70 was dried at $383 \mathrm{~K}$ in an oven, firstly at atmospheric pressure during $15 \mathrm{~h}$, and then $2 \mathrm{~h}$ in vacuum. Dried catalyst and $70 \mathrm{ml}$ of 1 -hexanol were charged into the reactor and when pressure achieved 2.1 MPa leaking problems were checked, and the reactor heated until reaction temperature was reached. This time was taken as the zero 
time of experiment. For $6 \mathrm{~h}$, liquid samples were analyzed hourly to obtain the variation in concentration over time of all compounds. The temperature was selected in the range $423-463 \mathrm{~K}$. The effect of stirring speed was studied among 50 and $800 \mathrm{rpm}$ for two different stirrers: a six blade dispersimax impeller and a four-blades axial up disperser. Catalyst mass used was between 1 and $3.5 \mathrm{~g}$.

In each experiment, 1-hexanol conversion $\left(\mathrm{X}_{\mathrm{HeOH}}\right)$, selectivity to DNHE ( $\left.\mathrm{S}_{\mathrm{DNHE}}\right)$, to alkenes $\left(\mathrm{S}_{\text {alkenes }}\right)$ and to branched ethers $\left(\mathrm{S}_{\text {ethers }}\right)$, and yield of DNHE with respect 1hexanol $\left(\mathrm{Y}_{\mathrm{DNHE}}\right)$ were computed by the expressions.

$$
\begin{aligned}
& X_{\mathrm{HeOH}}=\frac{\text { mole of } 1-\text { hexanol reacted }}{\text { initial mole of } 1-\text { hexanol }} \\
& S_{D N H E}=\frac{\text { mole of } 1-\text { hexanol reacted to form DNHE }}{\text { mole of } 1-\text { hexanol reacted }} \\
& Y_{D N H E}=\frac{\text { mole of } 1-\text { hexanol reacted to form } D N H E}{\text { initial mole of } 1-\text { hexanol }}=X_{H e O H} S_{D N P E}
\end{aligned}
$$

Finally, from the function of variation of $\mathrm{n}_{\mathrm{DNHE}}$ (number of DNHE moles produced) versus time, reaction rates of DNHE formation were calculated as:

$$
r_{D N H E}=\frac{1}{W}\left(\frac{d n_{D N H E}}{d t}\right)_{\mathrm{t}}\left[\frac{m o l D N H E}{k g \cdot h}\right]
$$

In all the experiments mass balance was accomplished within $\pm 5 \%$. 


\section{Results and discussion}

\subsection{Preliminary experiments}

Preliminary experiments were performed at $463 \mathrm{~K}$ to study the effect of stirring speed, particle size and catalyst mass on initial reaction rate. The influence of external mass transfer was checked by using two different mixers, namely a six-blade Dispersimax impeller and a four-blade axial up, at $463 \mathrm{~K}$ and using the commercial distribution of beads of A70. As Figure 1 shows, measured initial reaction rates were very similar, within the limits of the experimental error, in the range 100-600 rpm for both mixers. Although not shown, the same conclusion can be drawn when comparing 1-hexanol conversions. As a result, stirring speed was set at $500 \mathrm{rpm}$ in subsequent experiments using the 4-blade axial up mixer.

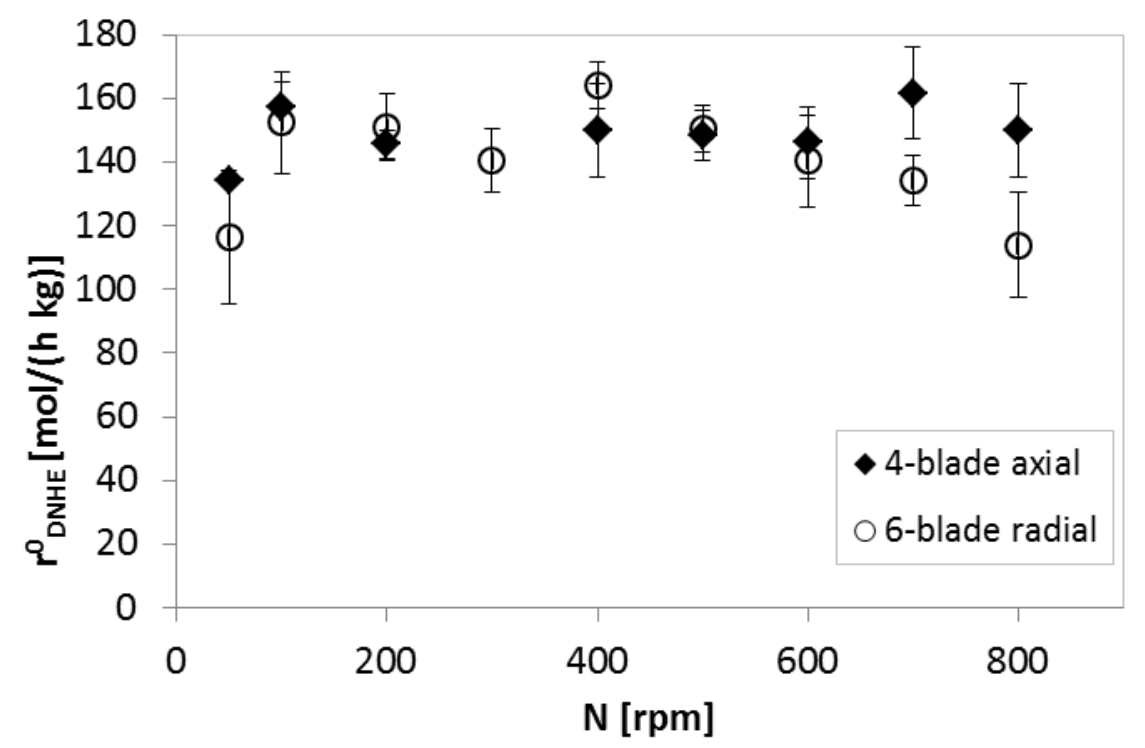

Figure 1. Effect of stirring speed on initial reaction rate (commercial distribution of bead size, 1 g A-70, 463K) 
In order to check the influence of catalyst particle size on the reaction rate, an experimental series was carried out at $463 \mathrm{~K}$ and $500 \mathrm{rpm}$ using beads of different particle size in the range $0.45-0.8 \mathrm{~mm}$. As shown in Figure 2, initial reaction rate is not influenced by the resin particle size within the limits of the experimental error. Probably, this effect is due to resin swelling by the water produced in the reaction, favoring diffusion to the active sites. Mean value of particle size distribution of commercial beads is close to $0.57 \mathrm{~mm}$ (open rhombus in Figure 2), so henceforth samples with commercial particle distribution size were used.

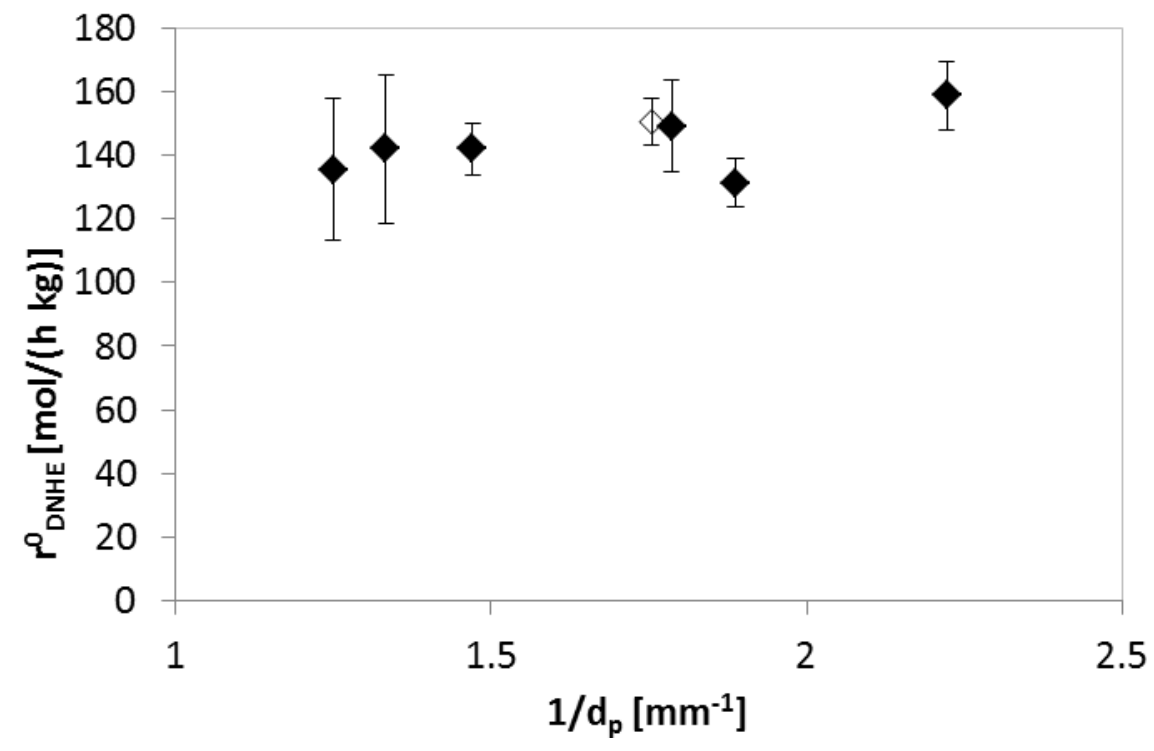

Figure 2. Influence of particle size on initial reaction rate. Open rhombus corresponds to the mean diameter of commercial beads $(\mathrm{T}=463 \mathrm{~K}, 500 \mathrm{rpm}, \mathrm{W}=1 \mathrm{~g})$

The effect of the catalyst mass was checked in a series of experiments carried out with catalyst amounts between 0.5 to $5 \mathrm{~g}$. Figure 3 shows that there is not any influence for catalyst amounts lesser than $3.5 \mathrm{~g}$, within the limits of the experimental error. For higher catalyst mass, initial reaction rate drops significantly. The fact that initial reaction rate 
decreases when the catalyst mass increases above $3.5 \mathrm{~g}$ could be explained by the loss of the proper hydrodynamic contact between solid and liquid. On increasing the catalyst mass, the slurry becomes heterogeneously suspended resulting in mass transfer effects that lessen the reaction rate. The same conclusion can be drawn from data of Figure 4, as explained below.

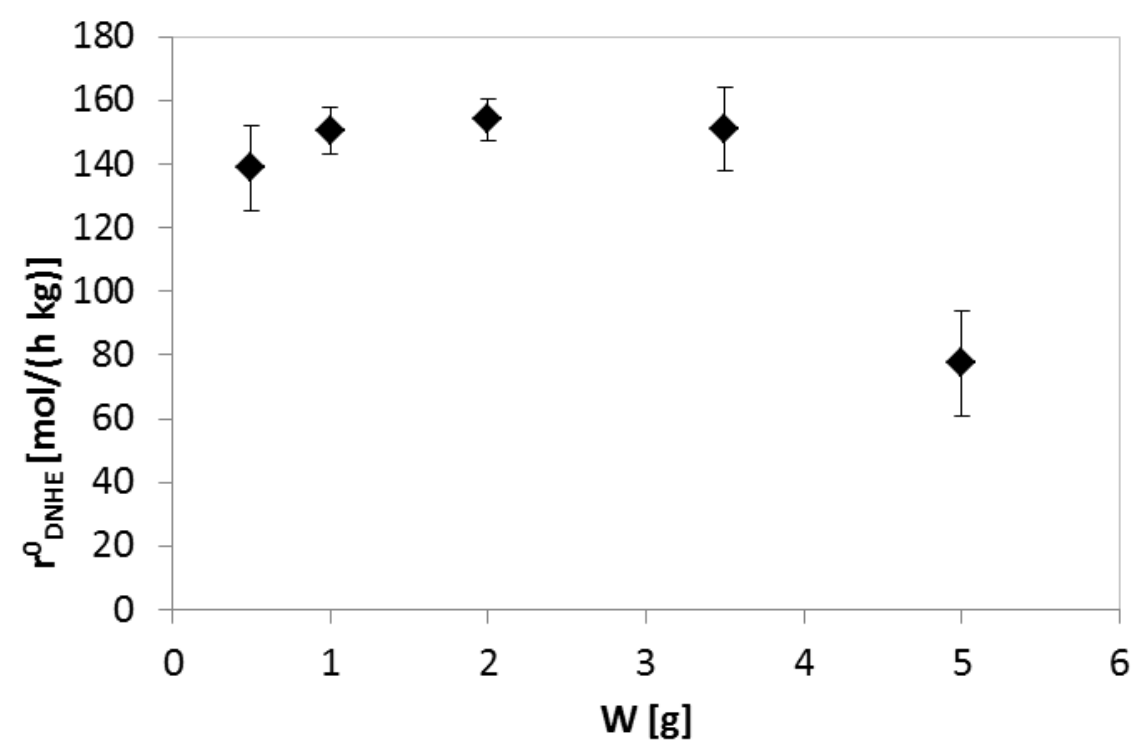

Figure 3. Effect of catalyst mass on the initial reaction rate at $463 \mathrm{~K}$ and $500 \mathrm{rpm}$ with commercial distribution of bead size of A70.

\subsection{Experiments starting with pure 1-hexanol}

Several experiments were performed in the temperature range $423-463 \mathrm{~K}$ on different amounts of Amberlyst 70 (0.5 to $3.5 \mathrm{~g})$ with the aim of complementing those reported in a previous work [23]. These new experiments confirm the reaction scheme proposed previously, being the intermolecular dehydration of 1-hexanol to DNHE and water the main reaction, and the intramolecular dehydration of 1-hexanol to 1-hexene (and subsequent double bond isomerization to (cis- and trans-) 2- and 3-hexene) the main 
side reaction. The reaction between 1-hexanol and any alkene leads to a branched ether, being these products detected in less extent, however.

Figure 4 plots 1-hexanol conversion versus the contact time $\left(\mathrm{W} \cdot \mathrm{t} / \mathrm{n}_{\mathrm{HeOH}}^{0}\right)$ with the aim of showing that experiments performed with different catalyst weight are consistent. According to the performance equation of a batch stirrer reactor in the absence of artifacts, at a constant temperature, all data have to be distributed along a unique curve. As seen in Figure 4, hexanol conversion increased with temperature and contact time, reaching a value of $85 \%$ at $463 \mathrm{~K}$ and $3.5 \mathrm{~g}$ of catalyst. Although the slope of curve of 1 $\mathrm{HeOH}$ conversion shown in Figure 4 seems to decrease, the system is far from equilibrium conditions since a value of $93 \%$ of conversion was achieved with $5 \mathrm{~g}$ of this catalyst at $463 \mathrm{~K}$. As commented before, this last value is not included in Figure 4 (and in the kinetic analysis) because of the initial reaction rate drop observed in Figure 3 for such amount of catalyst.

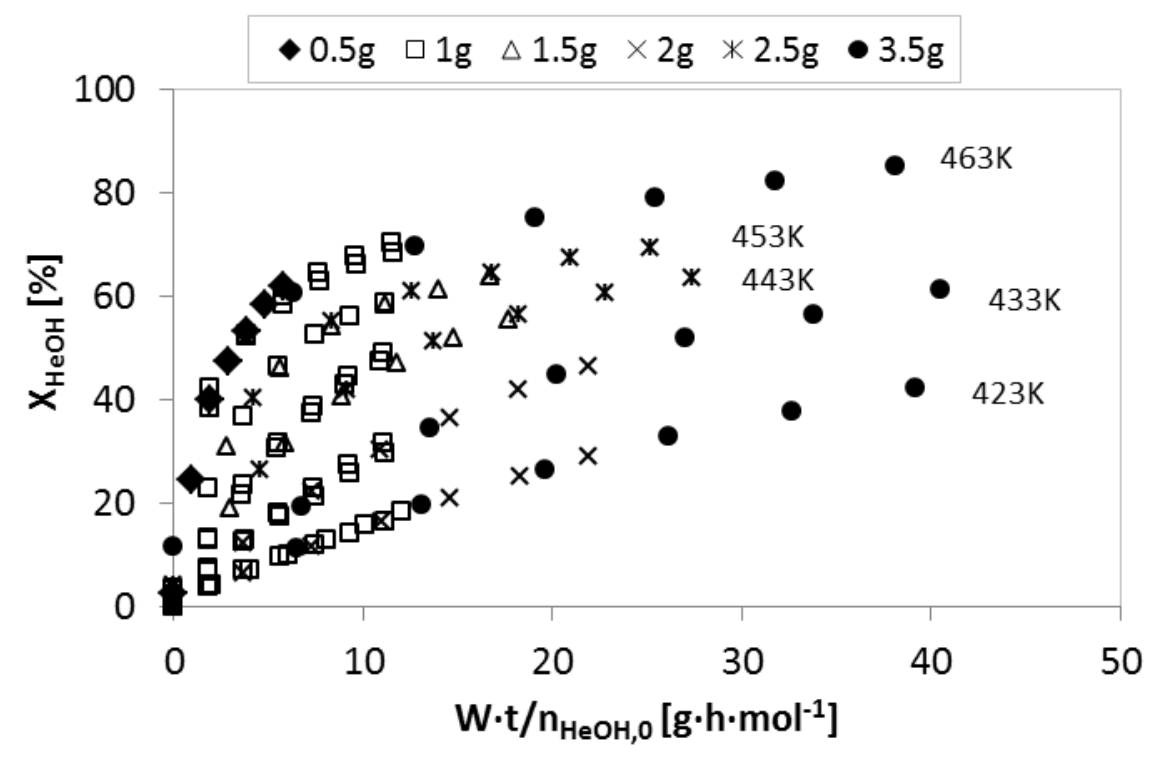

Figure 4. Plot of 1-hexanol conversion against $\mathrm{W} \cdot \mathrm{t} / \mathrm{n}_{\mathrm{HeOH}, 0}$ at different temperatures 
Selectivity to DNHE (see Figure 5 up) decreased with temperature and on increasing 1hexanol conversion, mainly due to the formation of $\mathrm{C}_{6}$ alkenes (see Figure 5 middle) and, in minor extension, branched ethers (see figure 5 bottom). The lowest selectivity to the desired ether (and the highest to $\mathrm{C}_{6}$ alkene products) was $83.1 \%$ at $463 \mathrm{~K}$ and $3.5 \mathrm{~g}$ of catalyst (13.5\% $\mathrm{C}_{6}$ alkenes and $3.4 \%$ branched ethers). Despite the decrease on the selectivity, yield to DNHE (not shown, $\mathrm{Y}_{\mathrm{DNHE}}=\mathrm{X}_{\mathrm{HeOH}} \cdot \mathrm{S}_{\mathrm{DNHE}}$ ) increased on increasing conversion (and time), reaching a maximum value of $71 \%$ at $463 \mathrm{~K}$ and $3.5 \mathrm{~g}$ of catalyst.
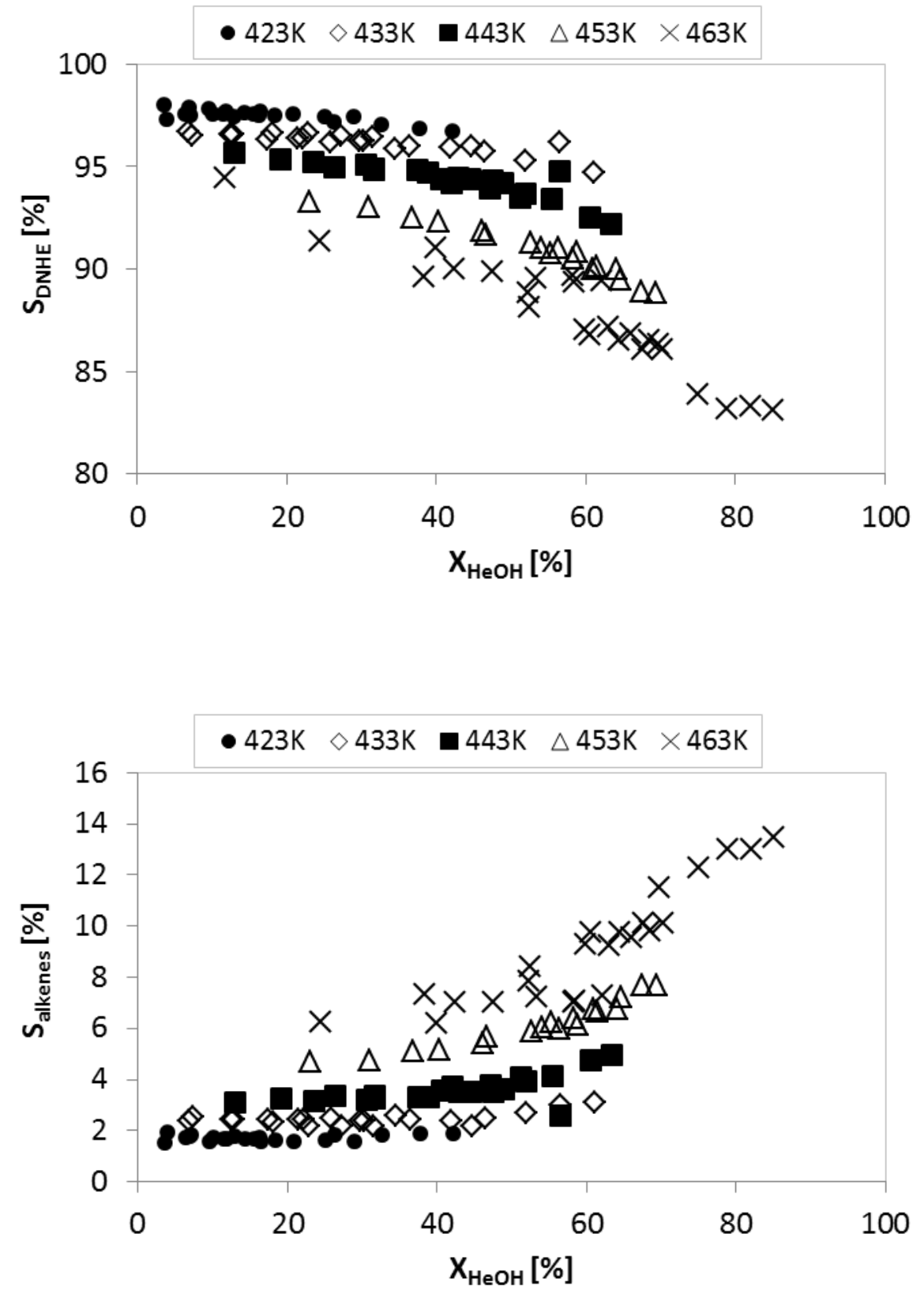


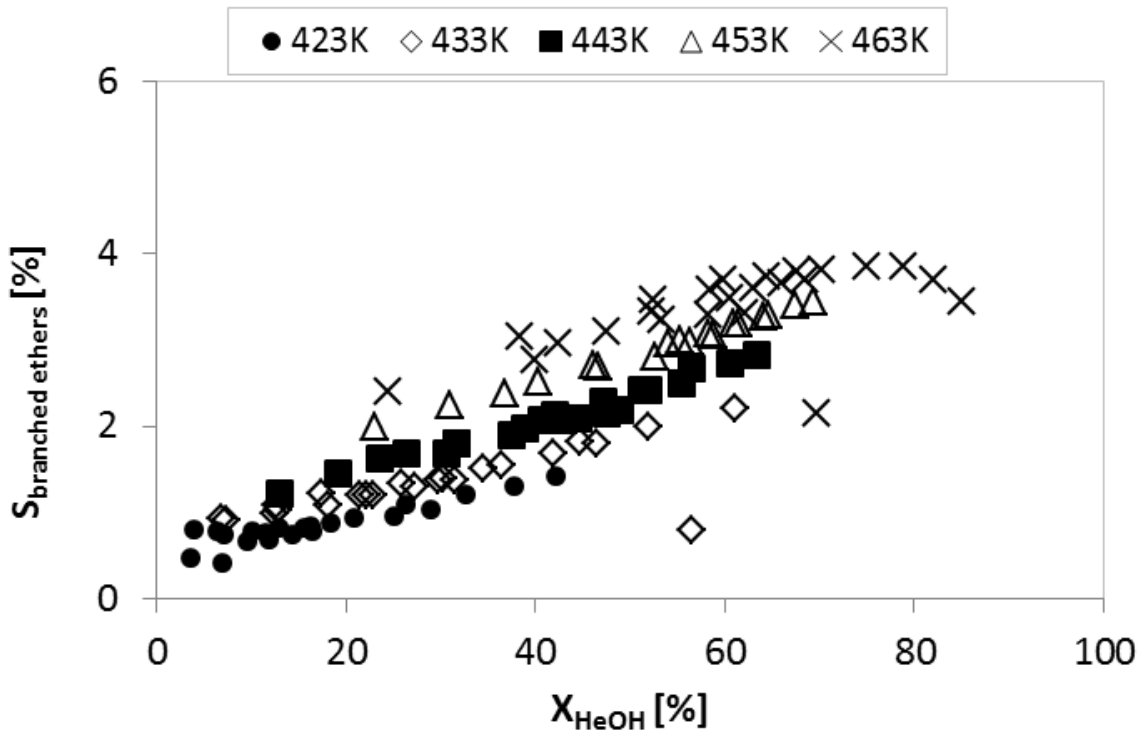

Figure 5. Selectivity to DNHE (top), $\mathrm{C}_{6}$ alkenes (middle) and branched ethers (bottom) versus 1-hexanol conversion at different temperatures

\subsection{Experiments starting with 1-hexanol/water and 1-hexanol/DNHE mixtures}

In order to stress the effect of water and DNHE on the kinetics of the reaction, a set of experiments starting with 1-hexanol/water (1-5 wt.\% water at $433 \mathrm{~K}, 1-7 \mathrm{wt} . \%$ water at 443K and 1-10 wt.\% water at 453K) and 1-hexanol/DNHE (5-20 wt.\% DNHE at 433463K) mixtures was performed at different temperatures.

Figure 6 (top) plots the initial reaction rate versus the initial wt.\% content of DNHE. As observed, the effect of the ether on the initial reaction rate is not remarkable, confirming that the weight of the ether activity on the denominator of the kinetic model should not be very important. On the other hand, initial reaction rate decreased sharply on increasing the initial amount of water, as Figure 6 (bottom) shows. In fact, a decrease of $90 \%$ of the initial reaction rate was observed at $463 \mathrm{~K}$ when $10 \mathrm{wt} . \%$ of water was added. This fact confirms the strong inhibiting effect of water on ion-exchange resins. 


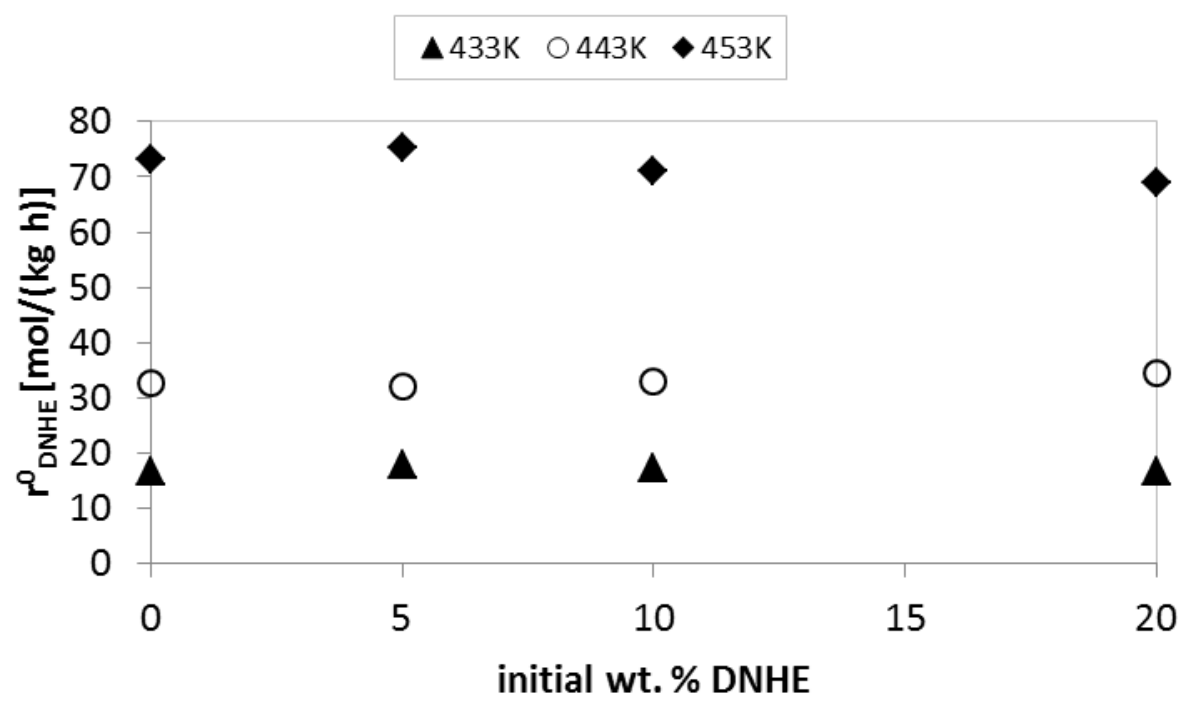

$\Delta 433 \mathrm{~K}$ ○443K • 453K

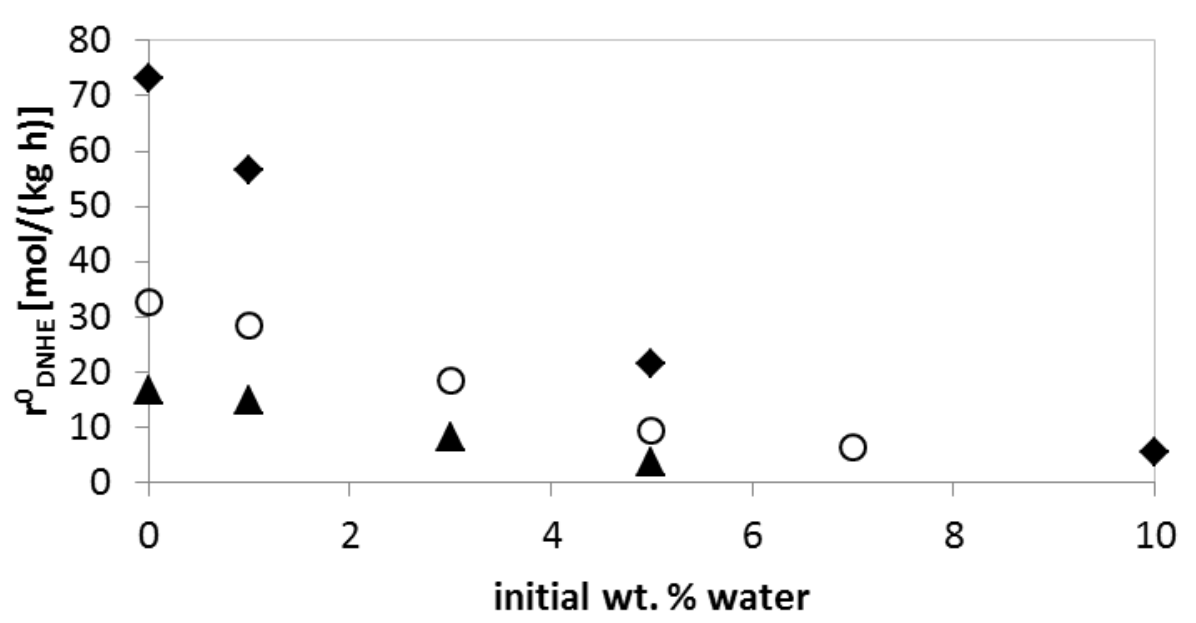

Figure 6. Effect of the initial concentration of DNHE (top) and water (bottom) on the initial reaction rate at different temperatures.

\subsection{Kinetic analysis}

As the reaction mixture is non-ideal [24], kinetic analysis is given in terms of activities of 1-hexanol $\left(a_{H}\right)$, DNHE $\left(a_{D}\right)$, and water $\left(a_{W}\right)$. Activity coefficients were computed by the UNIFAC-DORTMUND predictive method [27]. The dependence of the reaction 
rate as a function of $a_{H}, a_{D}$ and $a_{W}$ is shown in Figure 7 for those experiments starting with pure 1-hexanol. As seen, reaction rate increases on increasing $a_{H}$ in the entire range of explored activities and temperatures, whereas it decreases on increasing $a_{D}$ and $a_{W}$. These facts suggest that a hyperbolic model, based on a LHHW or ER mechanism, could explain satisfactorily rate data. Figure 7 (top) suggests that $a_{H}$ influences chiefly the numerator of such kinetic model, so promoting forward reaction. The ratedecreasing effect showed by $a_{D}$ and $a_{W}$ (Figures 7 (middle and bottom)) can be attributed to a preferential adsorption onto the resin of the ether and water, and also, as they are reaction products, to the enhancement of the reverse reaction as the system approaches to chemical equilibrium.

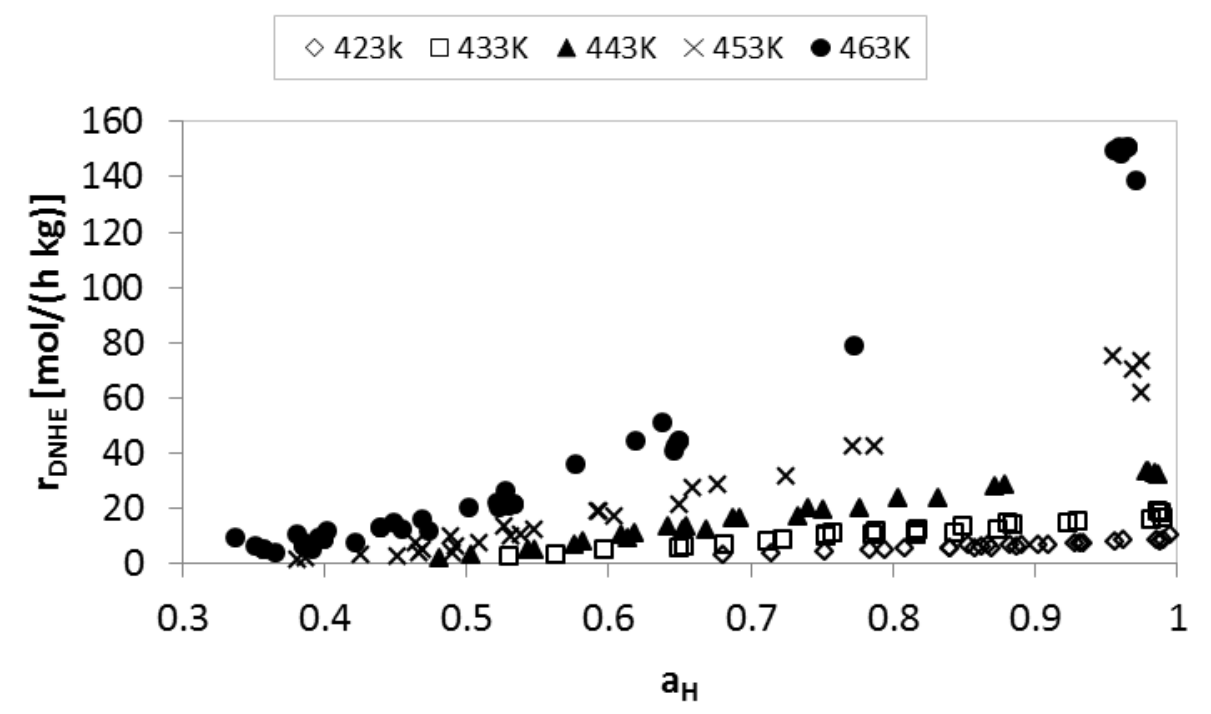



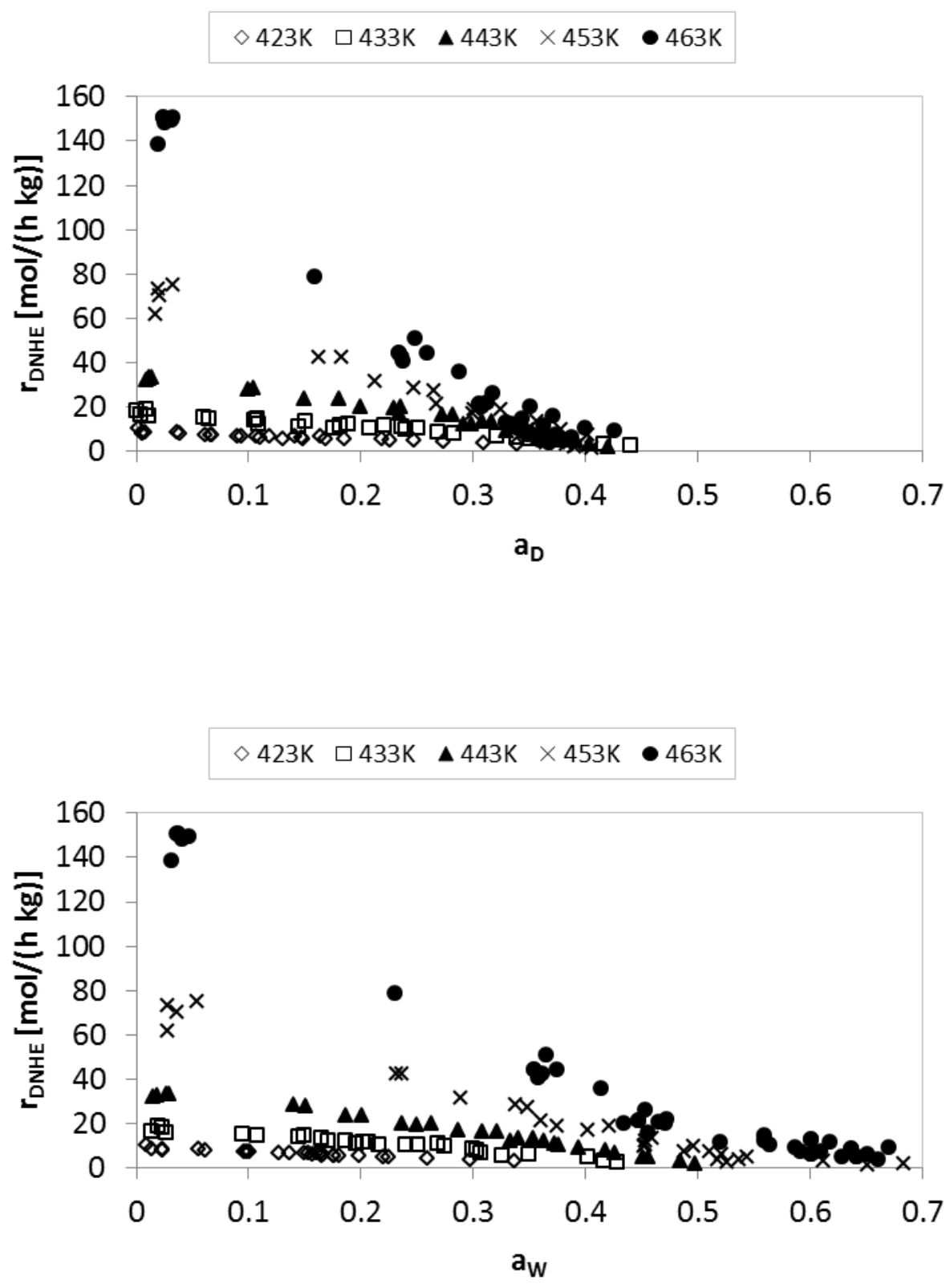

Figure 7. Reaction rate of DNHE synthesis as a function of 1-hexanol (top), DNHE (middle) and water (bottom) activities in the temperature range explored

Based on the analysis of the reaction rate dependence, considering the adsorptionreaction-desorption process and assuming that surface reaction is the rate-limiting step, the following kinetic models were obtained: 


$$
\begin{aligned}
r_{D N H E}= & \frac{\hat{k} \cdot K_{H}^{2}\left(a_{H}^{2}-\frac{a_{W} a_{D}}{K}\right)}{\left(1+K_{H} a_{H}+K_{D} a_{D}+K_{W} a_{W}\right)^{2}} \\
r_{D N H E}= & \frac{\hat{k} \cdot K_{H}\left(a_{H}^{2}-\frac{a_{W} a_{D}}{K}\right)}{1+K_{H} a_{H}+K_{D} a_{D}} \\
r_{D N H E}= & \frac{\hat{k} \cdot K_{H}\left(a_{H}^{2}-\frac{a_{W} a_{D}}{K}\right)}{1+K_{H} a_{H}+K_{W} a_{W}}
\end{aligned}
$$

Equation 6 stems from a LHHW mechanism in which two 1-hexanol molecules adsorbed on two adjacent active sites react to give the ether and water, both adsorbed on the resin surface. Equation 7 is based on an ER mechanism in which a molecule of 1hexanol from solution reacts with another molecule of 1-hexanol adsorbed on one active center to give the ether adsorbed on the resin surface, the water being released instantaneously to the liquid phase. Equation 8 stems from an analog ER mechanism but water remains adsorbed and the ether is released to the bulk phase. More detailed information about the mechanisms is found elsewhere [26,28].

On the basis of these equations, all possible kinetic models derived by considering one or more factors of adsorption term being negligible were fitted to rate data. For fitting purposes, all the models were grouped into two classes, depending on the number of free active centers (see Table 1):

(i) Class I, for which the number of free active centers is considered to be negligible compared to occupied ones. This fact implies that the unity present in the adsorption term is removed.

(ii) Class II, where that hypothesis is rejected. 
Table 1. Kinetic models tested with $n$ values ranging from 1 to 2

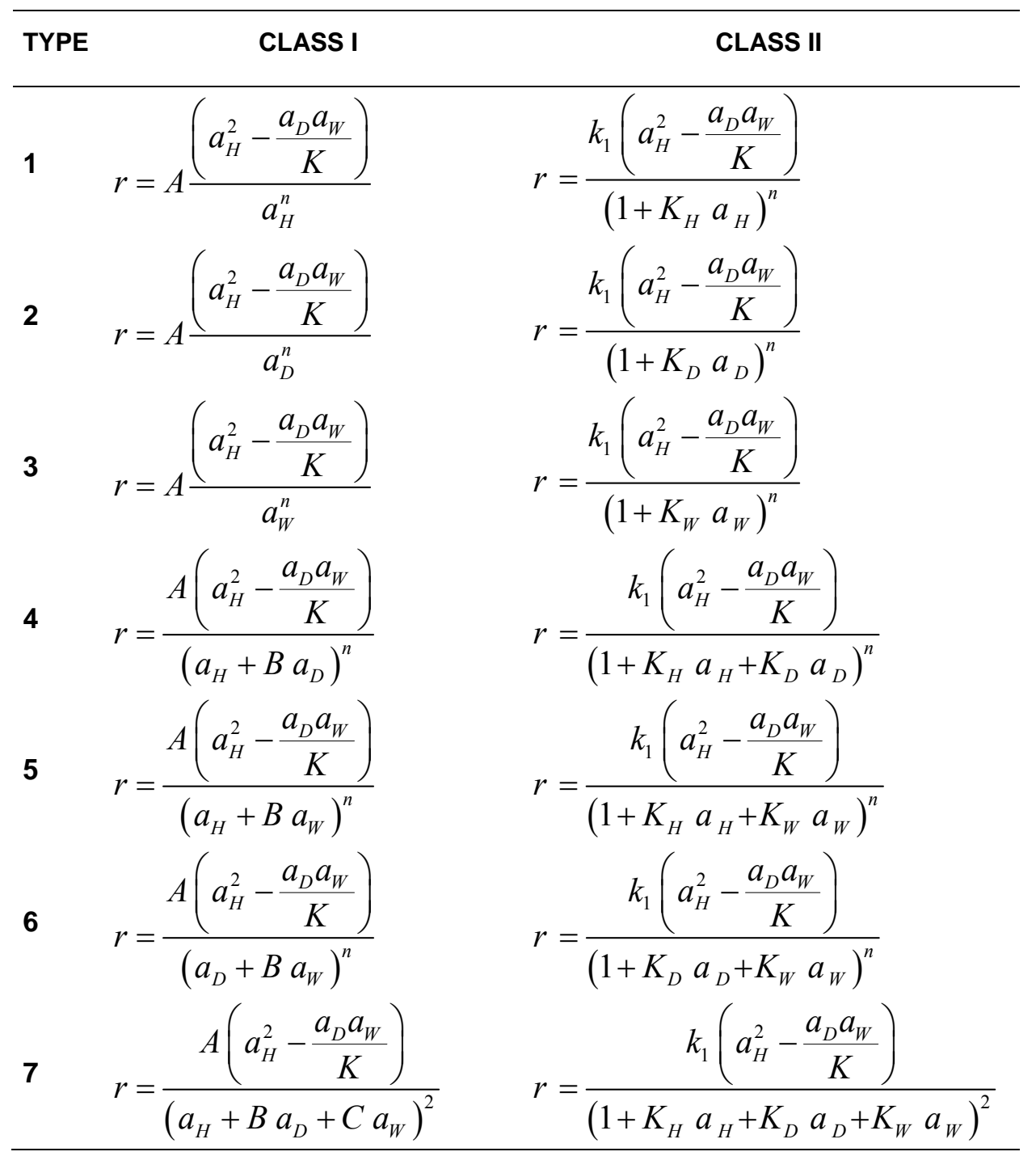

For models of Class I, the surface rate constant, $\hat{k}$, and the adsorption equilibrium constants, $K_{P}, K_{D}$, and $K_{W}$, have been grouped into factors, called A, B, and C, for mathematical fitting purposes. The particular form how constants are grouped depends on the mechanism (LHHW or ER) and the neglected adsorption term, if any.

Concerning the models of class II, $k_{l}$ is equal to $\hat{k} K_{H}^{2}$ for LHHW models and to $\hat{k} K_{H}$ for ER models. The temperature dependence of such factors was defined as follows: 


$$
A, B, C, k_{1}=\exp \left(b_{i}\right) \exp \left[-b_{i+1}\left(\frac{1}{T}-\frac{1}{\bar{T}}\right)\right]
$$

where $\bar{T}$ is the mean experimental temperature. To take into account the influence of the reverse reaction, the temperature dependence of the thermodynamic equilibrium constant, $K$, was computed as [24]

$$
K=\exp \left(\frac{1019.7}{T}+1.83\right)
$$

Fitted parameters of the models shown in Table 1 were b's, as appeared in Equation 9. The subtraction of the inverse of the mean experimental temperature was included to minimize the correlation among fitted parameters $b_{i}$ and $b_{i+l}$. From a mathematical point of view, the most suitable model is the one in which the minimum sum of squared residuals $(S S R)$, residuals randomness, and lower parameter correlation is obtained with the minimum number of fitted parameters. On the other hand, these parameters should have a physicochemical meaning, i.e. rate constant, and adsorption equilibrium constants, must increase, and decrease, respectively, with temperature, because reaction activation energy is positive and adsorption enthalpies negative. 


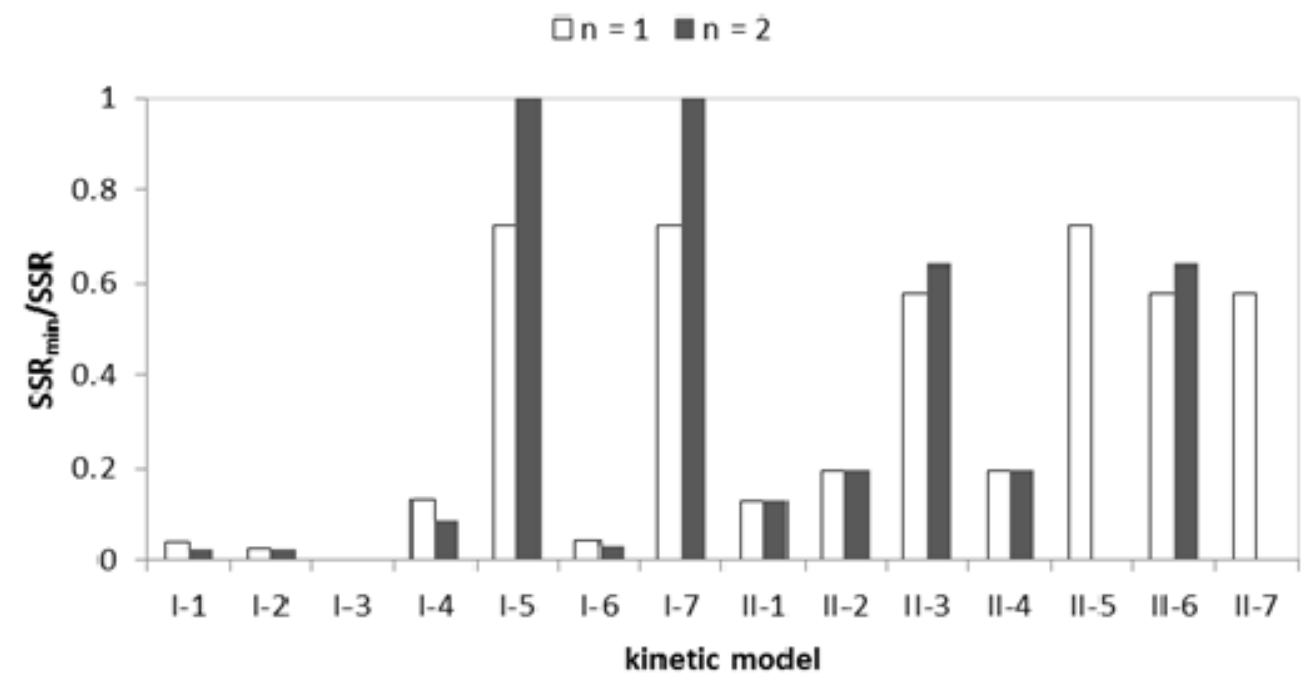

Figure 8. Comparison of the goodness of fit in terms of $\mathrm{SSR}_{\min } / \mathrm{SSR}$

Figure 8 shows the goodness of fit in terms of $S S R_{\min } / S S R$, where $S S R_{\min }$ is the minimum value obtained for the different models. Obviously, the model with $S S R_{\min } / S S R=1$ is the one with the minimum $S S R$, i.e. the best mathematical fit, while $S S R_{\min } / S S R$ tends to zero for worse fits. Models Class I type 3 (from now coded as I-3) with $n=1$ and 2, II-5 (n=2) and II-7 ( $n=2)$ did not converge or led to results without physicochemical meaning during the fitting procedure. A closer look to models I-5 $(\mathrm{n}=2)$ and $\mathrm{I}-7(\mathrm{n}=2)$ reveals that the introduction of the term $B \cdot a_{D}$ in the denominator of model I-7 does not upgrade the mathematical fit obtained with model I-5 $(n=2)$. As seen in Figure 8, using the mathematical criterion of minimum SSR the best model was I-5 $(n=2)$ :

$r=\frac{A\left(a_{H}^{2}-\frac{a_{D} a_{W}}{K_{e q}}\right)}{\left(a_{H}+B a_{W}\right)^{2}}$ 
Equation 11 stems from a LHHW mechanism, assuming that DNHE adsorption and the fraction of free active sites are negligible. The effect of water is explained by the competitive adsorption with 1-hexanol. Table 2 shows the values of fitted parameters of Equation 11 and their standard errors, estimated by means of the linear least squares method with $95 \%$ confidence level. For this model, $A=\hat{k}$ and $\mathrm{B}=\mathrm{K}_{\mathrm{w}} / \mathrm{K}_{\mathrm{H}}$. Therefore, from $b_{2}$ the activation energy can be computed, whereas from $b_{3}$ and $b_{4}$ the alcohol/water ratio of equilibrium adsorption constants can be calculated over the entire temperature range. B's values are higher than unity at all temperatures, which means that the adsorption equilibrium constant was higher for water than for 1-hexanol, i.e. water has more affinity for the active sites than 1-hexanol.

Table 2. Parameters of the fitting procedure of Equation $11\left(b_{1}\right.$ and $b_{2}$ corresponding to $A$, and $b_{3}$ and $b_{4}$ corresponding to $B$, according to Equation 9$)$ and Equation $15\left(b_{1}\right.$ and $\mathrm{b}_{2}$ corresponding to $\hat{k}_{o}$ )

\begin{tabular}{lcc}
\hline & Equation 11 & Equation 15 \\
\hline $\mathrm{b} 1$ & $3.67 \pm 0.03$ & $3.71 \pm 0.03$ \\
$\mathrm{~b} 2$ & $15078 \pm 401$ & $14524 \pm 304$ \\
$\mathrm{~b} 3$ & $0.42 \pm 0.06$ & \\
$\mathrm{~b} 4$ & $2427 \pm 829$ & \\
$\mathrm{~K}_{\mathrm{w} 1}$ & & $529 \pm 22$ \\
$\mathrm{~K}_{\mathrm{w} 2}$ & & $1452 \pm 364$ \\
$\mathrm{~K}_{\alpha}$ & & $594 \pm 44$ \\
$\mathrm{E}_{\mathrm{a}}(\mathrm{kJ} / \mathrm{mol})$ & $125 \pm 3$ & $121 \pm 3$ \\
$\mathrm{SSR}$ & 2853 & 2496 \\
\hline
\end{tabular}


Equation 11 satisfactorily represents experimental data as a whole (see Figure 9 top).

However some deviations are observed for low reaction rate values (see Figure 9 bottom), being clearly overestimated by the proposed model. These overestimated values correspond to experimental data with high water content, so the effect of water is not well explained only by the competitive adsorption proposed by equation 11 . Furthermore, the residual plot shown in Figure 10 (top) is clearly biased. On the other hand, it should be highlighted that the same kinetic model was proposed in a previous work for the analog reaction system of 1-pentanol dehydration to di-n-pentyl ether and water [28]. So for these reacting systems, the bimolecular dehydration of two molecule of alcohol to produce one molecule of ether and water, the largest and least polar ether molecule is rapidly released to the bulk phase, whereas water remains adsorbed on the active centers.

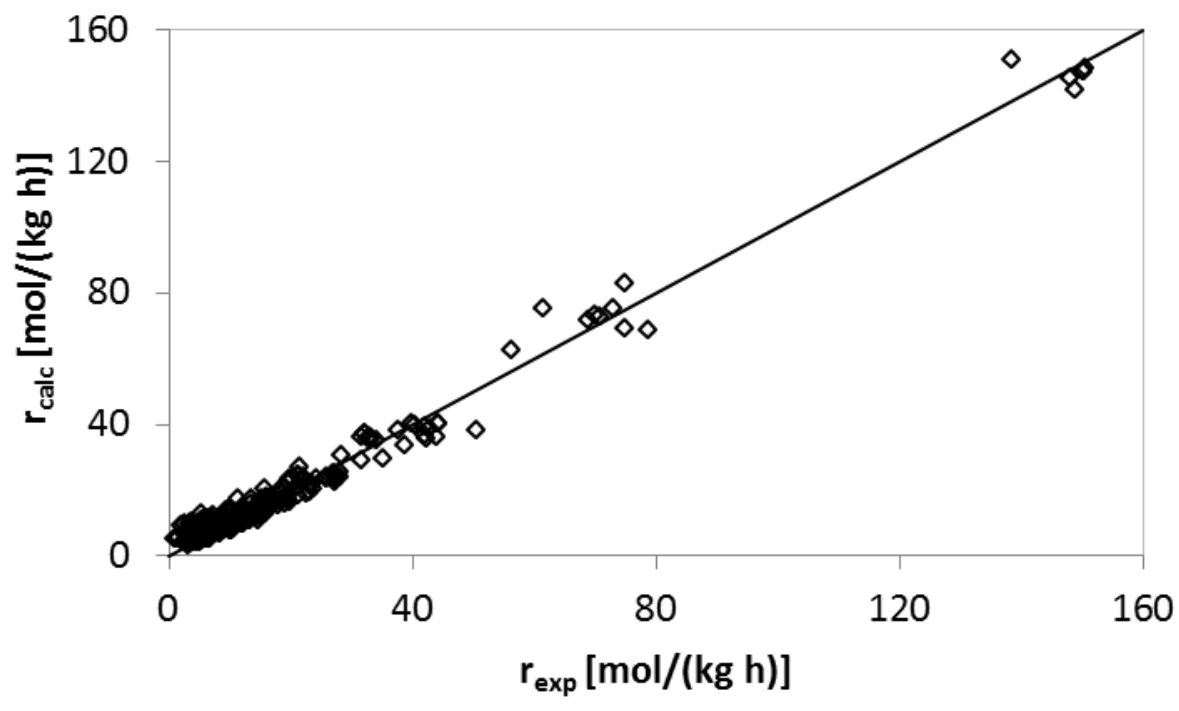




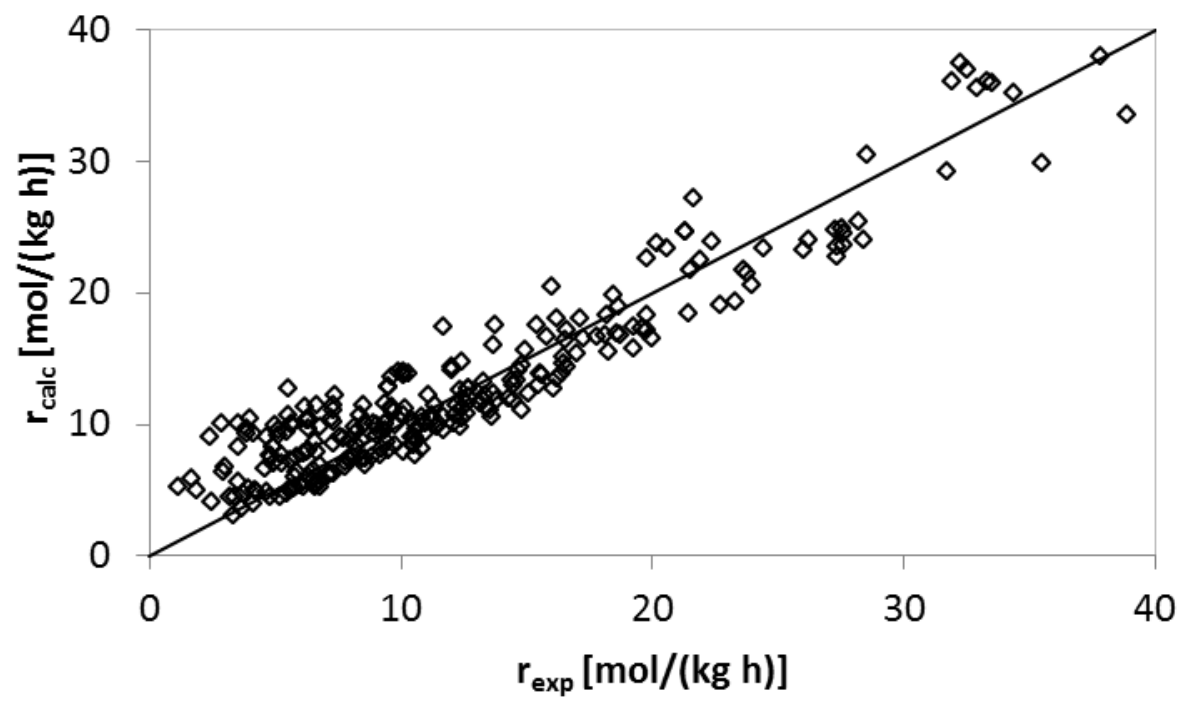

Figure 9. Calculated reaction rates by equation 11 versus experimental values in the whole rate data (top) and low values (bottom).

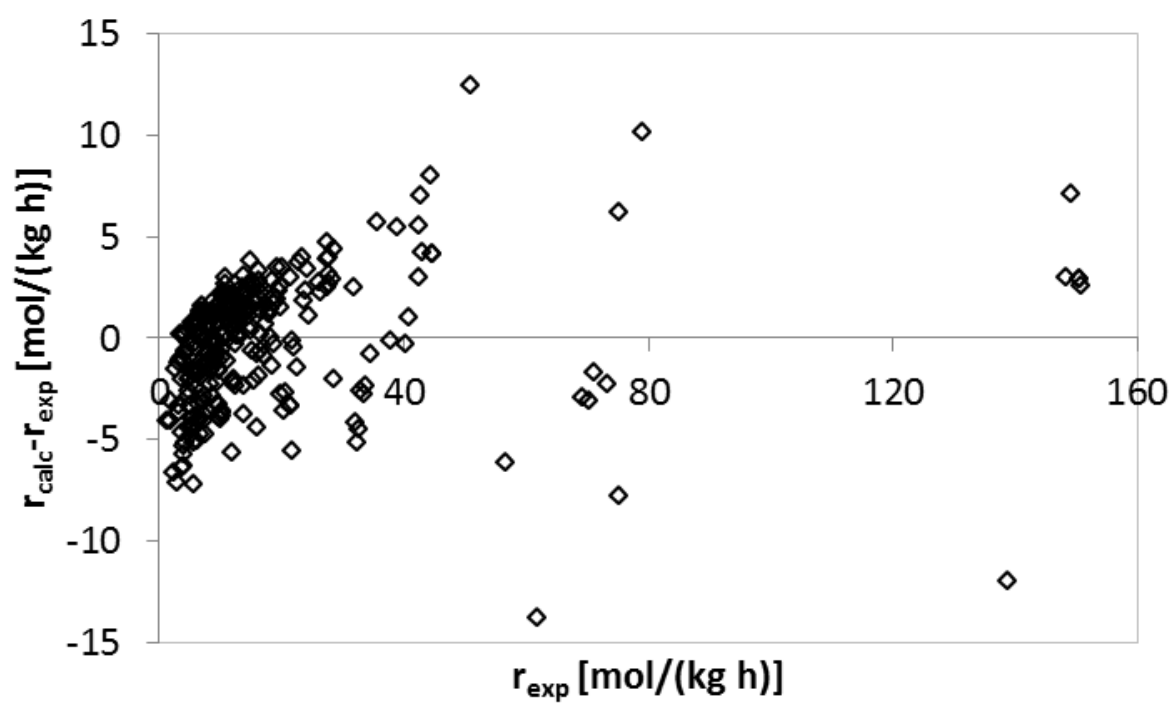

Figure 10 (top). Residuals distribution for Equation 11 (top) and Equation 15 (bottom)

\subsection{Modification of the kinetic model}

As found elsewhere in two different studies [22,28], a new approach was undertaken to model the effect of water on the reaction rate, considering that it blocks $-\mathrm{SO}_{3} \mathrm{H}$ groups. 
The rate constant, $\hat{k}$, is a function of the total amount of available sites. Water effect was modeled by splitting $\hat{k}$ into a "true" rate constant, $\hat{k}_{o}$, and a function of the fraction of sites free of water $\left(1-\theta_{W}\right)$ which depends on $a_{W}$ and temperature. Analogously to du Toit and Nicol's work [22], a Freundlich adsorption isotherm was used to consider the amount of adsorbed water, where $n$ are the sites taking part in the rate-limiting step.

$$
\begin{aligned}
& \hat{k}=\hat{k}_{o} \cdot f\left(a_{W}, T\right)=\hat{k}_{o}\left(1-K_{W} a_{W}^{1 / \alpha}\right)^{n} \\
& \text { where } \alpha=\frac{K_{\alpha}}{T} \\
& \text { and } K_{W}=\frac{K_{W 1}}{T} \exp \left[-K_{W 2}\left(\frac{1}{T}-\frac{1}{\bar{T}}\right)\right]
\end{aligned}
$$

Models of Table 1, modified by including the correction factor defined by Equation 12, were fitted to the rate data. Fitted parameters were $b$ 's from Equation $9, K_{\alpha}$ from Equation 13, and $K_{W 1}$ and $K_{W 2}$ from Equation 14. Therefore, three additional parameters where involved in the fitting procedure. This fact and the presence of water activity in the correction factor led to an improvement of the fit obtained by Equation 11 with some models. But many of them were rejected due to the high uncertainty of the estimated parameters, which indicates the over parameterization of the model. The selected modified kinetic model was:

$$
r=\frac{A\left(a_{H}^{2}-\frac{a_{D} a_{W}}{K_{e q}}\right)}{a_{H}}\left(1-K_{W} a_{W}^{1 / \alpha}\right)
$$

Equation 15 corresponds to the modified model I-1 $(n=1)$, and stems from an ER mechanism, by assuming adsorption of DNHE and water and free active sites 
negligible. The effect of water is taken into account by considering that it blocks or inhibits the active centers, which has a reducing effect on the global rate constant value. Again, this model was also the best fit for 1-pentanol system [28], confirming the similitude of both reacting systems.
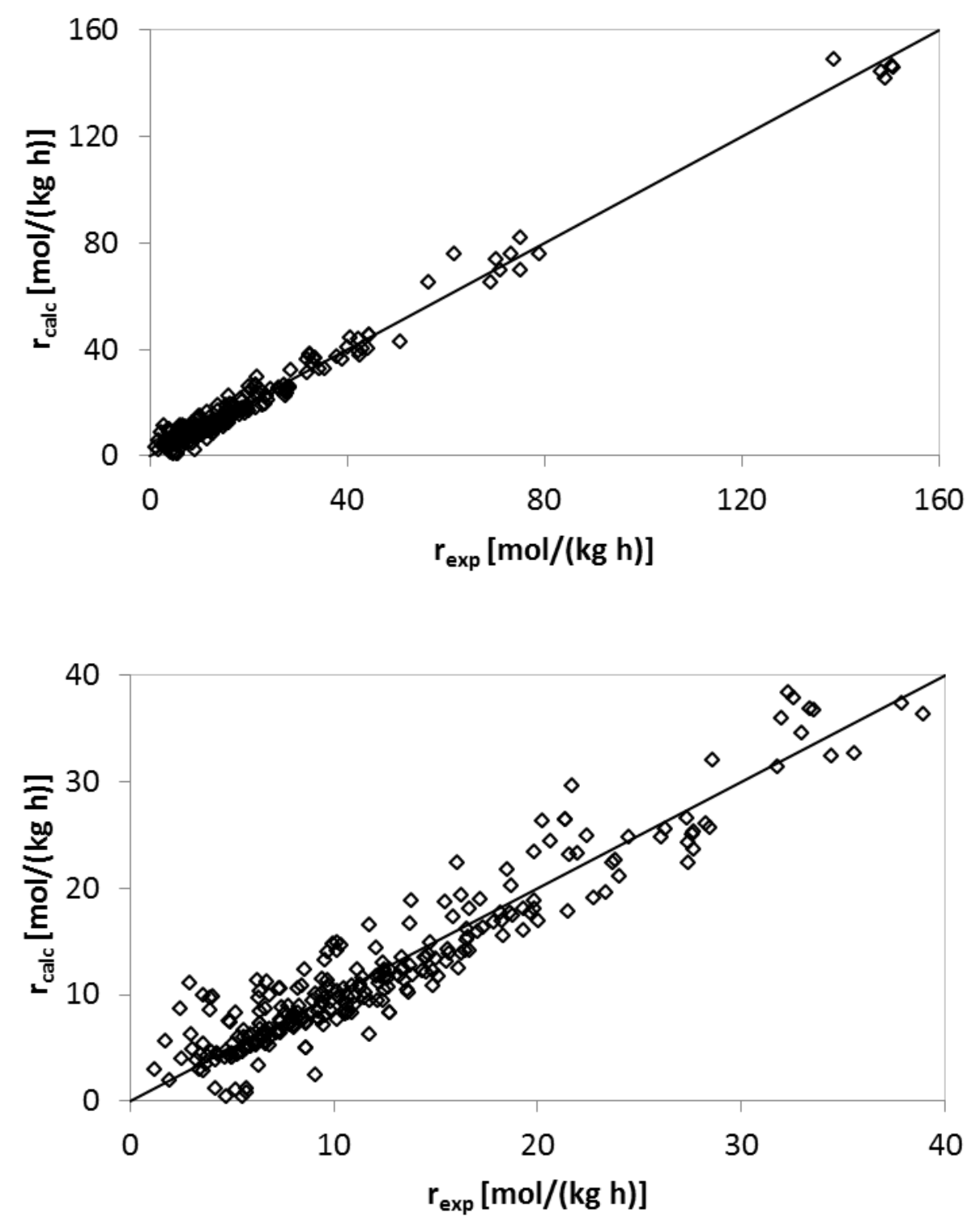

Figure 11. Calculated reaction rates by equation 15 versus experimental values in the whole rate data (top) and low values (bottom). 
Table 2 also shows the values of fitted parameters of Equation 15. Equation 15 improved the SSR by $12 \%$ and, as seen in Figure 11 (bottom), the prediction of rate data is clearly enhanced for low rate values (and high water content) and the model presents a good residual distribution (Figure 10 (bottom)). The improvement of the fit could be attributed to the fact that Equation 15 has one more parameter than Equation 11 and/or that the mathematical expression for water adsorption is more flexible to fit rate data. Since apparent activation energies for both models are very similar, water adsorption does not influence the sensitivity of the reaction rate to temperature. As seen in Table 3, Equation 15 presents a more desirable cross-correlation matrix.

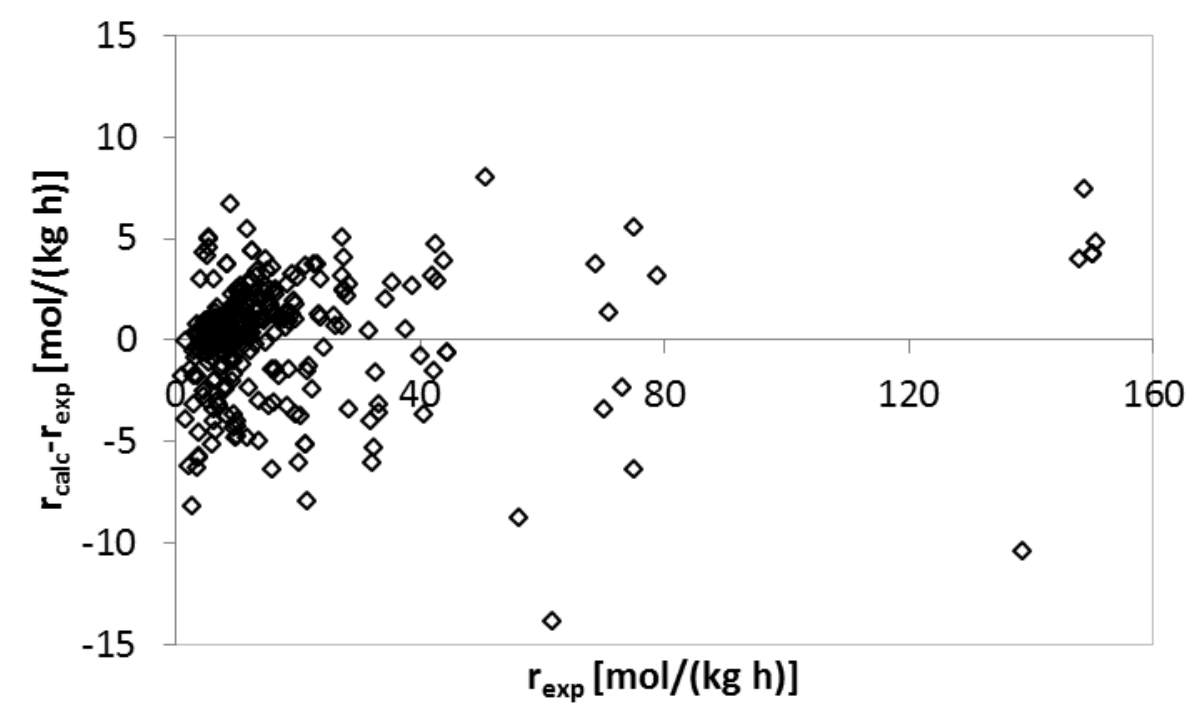

Figure 10 (bottom). Residuals distribution for Equation 11 (top) and Equation 15 (bottom)

The Freundlich isotherm approach expects that $\alpha$ decreases almost linearly with temperature and $K_{W}$ is non-dependent $[22,29]$. Moreover, $\alpha$ should be larger than 1. From $K_{W i}$ and $K_{\alpha}$ values shown in Table 2, $\alpha$ and $K_{W}$ can be computed (Equations 13 and 14) and plotted versus temperature (Figure 12). As seen, $\alpha$ is higher than unity and it decreases with temperature, but $K_{W}$ increases by $20 \%$ from $423 \mathrm{~K}$ to $463 \mathrm{~K}$. These points suggest that the fitting improvement is due to the flexibility of the power 
expression for $\theta_{W}$ and to the fact that the fitting procedure involved more parameters rather than to a fundamental insight of Freundlich isotherm. Thus, the kinetic model proposed by Equation 15 is a pseudo empirical model rather than a mechanistic one. However, if the correction factor is considered in terms of catalyst deactivation, $K_{W}$ could be considered as a deactivation constant. Consequently, from its temperature dependence a pseudoactivation energy for the water deactivation process of $12 \pm 3$ $\mathrm{kJ} / \mathrm{mol}$ could be computed.

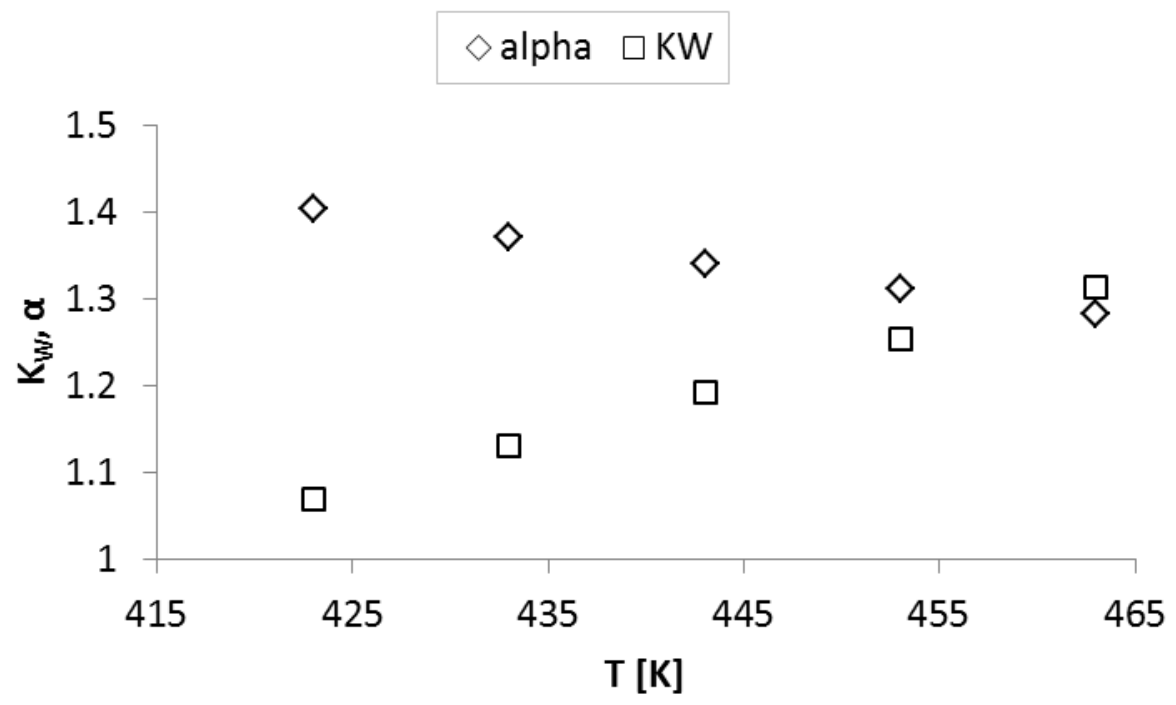

Figure 12. Evolution of computed $K_{W}$ and $\alpha$ from optimum parameters over temperature

Table 3. Correlation matrix of fitted parameters for Equation $11\left(b_{i}\right.$ are the fitting parameters of factors A and B of the model) and Equation $15\left(b_{i}\right.$ and $K_{W i}$ are the fitting parameters of factors $\mathrm{A}$ and $K_{W}$ of the model), respectively.

\begin{tabular}{ccccc}
\hline \multicolumn{5}{c}{ Equation 11 } \\
\hline & $\mathrm{b}_{1}$ & $\mathrm{~b}_{2}$ & $\mathrm{~b}_{3}$ & $\mathrm{~b}_{4}$ \\
\hline $\mathrm{b}_{1}$ & 1 & & & \\
$\mathrm{~b}_{2}$ & -0.91 & 1 & &
\end{tabular}




\begin{tabular}{ccccc}
$\mathrm{b}_{3}$ & 0.77 & -0.71 & 1 & \\
$\mathrm{~b}_{4}$ & -0.67 & -0.75 & -0.89 & 1 \\
\hline
\end{tabular}

\begin{tabular}{cccccc}
\hline \multicolumn{5}{c}{ Equation 15 } \\
\hline & $\mathrm{b}_{1}$ & $\mathrm{~b}_{2}$ & $\mathrm{~K}_{\mathrm{W} 1}$ & $\mathrm{~K}_{\mathrm{W} 2}$ & $\mathrm{~K}_{\alpha}$ \\
\hline $\mathrm{b}_{1}$ & 1 & & & & \\
$\mathrm{~b}_{2}$ & -0.72 & 1 & & & \\
$\mathrm{~K}_{\mathrm{W} 1}$ & -0.17 & -0.32 & 1 & & \\
$\mathrm{~K}_{\mathrm{W} 2}$ & 0.44 & -0.58 & 0.60 & 1 & \\
$\mathrm{~K}_{\alpha}$ & 0.67 & -0.09 & -0.72 & 0.06 & 1 \\
\hline
\end{tabular}

\section{Conclusions}

Two approaches are used to explain the kinetics of the dehydration of 1-hexanol to DNHE and water. First, a classical LHHW model, based on a mechanism in which the surface reaction between two adjacent adsorbed molecules of 1-hexanol is the ratelimiting step. The effect of water is accounted as a strong competition with 1-hexanol for the active sites, both in the denominator of the model. In a second approach, a modified ER model is proposed, based on a mechanism in which the surface reaction between one adsorbed molecule of alcohol and one from the bulk phase is the ratelimiting step, with a significant contribution of 1-hexanol in the denominator. The inhibition effect of water is taken into account with a factor that modifies the intrinsic rate constant. Both models fitted data satisfactorily, although the best results were obtained with the modified model. The activation energy was $125 \pm 3$ for the LHHW and $121 \pm 3$ for the modified ER one.

\section{Acknowledgments}


Financial support was provided by the State Education, Universities, Research \& Development Office of Spain (project CTQ2004-01729/PPQ). The authors thank Rohm and Haas France for providing A-70 thermally ion exchange resin.

\section{Nomenclature}

$a_{j} \quad$ activity of compound $\mathrm{j}$

$A, B, C, k_{1} \quad$ grouped factors for fitting purposes

$b_{i} \quad$ fitted parameters

$E_{a} \quad$ activation energy $(\mathrm{kJ} / \mathrm{mol})$

$\hat{k} \quad$ intrinsic rate constant $\left(\mathrm{mol} \mathrm{h}^{-1} \mathrm{~g}^{-1}\right)$

$\hat{k}_{0} \quad$ intrinsic rate constant without the effect of water $\left(\mathrm{mol} \mathrm{h}^{-1} \mathrm{~g}^{-1}\right)$

$K_{j} \quad$ adsorption equilibrium constant of $\mathrm{j}$

$K \quad$ thermodynamic equilibrium constant

$K_{\alpha}, K_{w} \quad$ Freundlich-type correction factor constants

$n \quad$ number of active sites involved in the surface reaction

$n_{D N H E} \quad$ number of DNHE moles

$r_{D N H E} \quad$ reaction rate of DNHE synthesis $\left(\mathrm{mol} \mathrm{h}^{-1} \mathrm{~kg}^{-1}\right)$

$\mathrm{S}_{\mathrm{j}} \quad$ selectivity to $\mathrm{j}(\%)$

SSR sum of squared residuals

t time (h)

$T \quad$ temperature $(\mathrm{K})$

$\bar{T} \quad$ mean experimental temperature $(\mathrm{K})$

$\mathrm{X}_{\mathrm{HeOH}} \quad$ conversion of 1-hexanol (\%)

$Y_{\text {DNHE }} \quad$ DNHE yield

W $\quad$ catalyst mass $(\mathrm{g})$ 
Greek letters

$\theta_{\mathrm{W}} \quad$ fraction of active centers occupied by water

Subscripts

$\begin{array}{ll}\text { Alkenes } & \mathrm{C}_{6} \text { alkenes } \\ \text { Branched ethers } & \mathrm{C}_{6} \text { branched ethers } \\ \text { D,DNHE } & \text { di-n-hexyl ether } \\ \mathrm{H}, \mathrm{HeOH} & \text { 1-hexanol } \\ \text { W } & \text { water }\end{array}$

\section{References}

[1] J.C. Gee, S.T. Williams, Dimerization of linear olefins on Amberlyst ${ }^{\circledR}$ 15: Effects of chain length and double-bond position, Journal of Catalysis 303 (2013) 1-8.

[2] F. Aiouache, S. Goto, Sorption effect on kinetics of etherification of tert-amyl alcohol and ethanol, Chemical Engineering Science 58 (2003) 2065-2077.

[3] I. Hoek, T.A. Nijhuis, A.I. Stankiewicz, J.A. Moulijn, Kinetics of solid acid catalysed etherification of symmetrical primary alcohols: Zeolite BEA catalysed etherification of 1-octanol, Applied Catalysis A: General 266 (2004) 109-116.

[4] F. Aiouache, S. Goto, Kinetic study on 2-methyl-1-butanol dehydration catalysed by ion exchange resin, J. Chem. Eng. Japan 35 (2002) 436-442. 
[5] B. Sow, S. Hamoudi, M. Hassan Zahedi-Niaki, S. Kaliaguine, 1-butanol etherification over sulfonated mesostructured silica and organo-silica, Microporous and Mesoporous Materials 79 (2005) 129-136.

[6] S. Akyalçin, M.R. Altiokka, Kinetics of esterification of acetic acid with 1-octanol in the presence of Amberlyst 36, Applied Catalysis A: General 429-430 (2012) 79-84.

[7] X. Shan, Z. Cheng, P. Yuan, Reaction kinetics and mechanism for hydration of cyclohexene over ion-exchange resin and H-ZSM-5, Chem. Eng. J. 175 (2011) 423-432.

[8] V.J. Cruz, R. Bringué, F. Cunill, J.F. Izquierdo, J. Tejero, M. Iborra, C. Fité, Conversion, selectivity and kinetics of the liquid-phase dimerisation of isoamylenes in the presence of $\mathrm{C} 1$ to $\mathrm{C} 5$ alcohols catalysed by a macroporous ion-exchange resin, Journal of Catalysis 238 (2006) 330-341.

[9] M.L. Honkela, A.O.I. Krause, Kinetic modeling of the dimerization of isobutene, Industrial and Engineering Chemistry Research 43 (2004) 3251-3260.

[10] S. Talwalkar, M. Chauhan, P. Aghalayam, Z. Qi, K. Sundmacher, S. Mahajani, Kinetic studies on the dimerization of isobutene with ion-exchange resin in the presence of water as a selectivity enhancer, Industrial and Engineering Chemistry Research 45 (2006) 1312-1323.

[11] S. Thotla, V. Agarwal, S.M. Mahajani, Aldol condensation of acetone with reactive distillation using water as a selectivity enhancer, Industrial and Engineering Chemistry Research 46 (2007) 8371-8379.

[12] B.C. Gates, W. Rodriguez, General and specific acid catalysis in sulfonic acid resin, Journal of Catalysis 31 (1973) 27-31. 
[13] R.A. Reinicker, B.C. Gates, Bisphenol A synthesis: kinetics of the Phenol-Acetone condensation reaction catalyzed by sulfonic acid resin., AIChE J. 20 (1974) 933-940.

[14] H.T.R. Teo, B. Saha, Heterogeneous catalysed esterification of acetic acid with isoamyl alcohol: Kinetic studies, Journal of Catalysis 228 (2004) 174-182.

[15] J.M. Aragón, J.M.R. Vegas, L.G. Jodra, Catalytic behavior of macroporous resins in catalytic processes with water production. Activation and inhibition effects in the kinetics of the self-condensation of cyclohexanone, Industrial and Engineering Chemistry Research 32 (1993) 2555-2562.

[16] M.-. Lee, H.-. Wu, H.-. Lin, Kinetics of catalytic esterification of acetic acid and amyl alcohol over dowex, Industrial and Engineering Chemistry Research 39 (2000) 4094-4099.

[17] M.-. Lee, J.-. Chiu, H.-. Lin, Kinetics of catalytic esterification of propionic acid and n-butanol over Amberlyst 35, Industrial and Engineering Chemistry Research 41 (2002) 2882-2887.

[18] M. Kawase, Y. Inoue, T. Araki, K. Hashimoto, The simulated moving-bed reactor for production of bisphenol A, Catalysis Today 48 (1999) 199-209.

[19] G.G. Podrebarac, F.T.T. Ng, G.L. Rempel, A kinetic study of the aldol condensation of acetone using an anion exchange resin catalyst, Chemical Engineering Science 52 (1997) 2991-3002.

[20] B.-. Yang, M. Maeda, S. Goto, Kinetics of liquid phase synthesis of tert-amyl methyl ether from tert-amyl alcohol and methanol catalyzed by ion exchange resin, Int $\mathbf{J}$ Chem Kinet 30 (1998) 137-143. 
[21] U. Limbeck, C. Altwicker, U. Kunz, U. Hoffmann, Rate expression of THF synthesis on acidic ion exchange resin, Chemical Engineering Science 56 (2001) 21712178.

[22] E. du Toit, W. Nicol, The rate inhibiting effect of water as a product on reactions catalysed by cation exchange resins: Formation of mesityl oxide from acetone as case study, Applied Catalysis A: General 277 (2004) 219-225.

[23] E. Medina, R. Bringué, J. Tejero, M. Iborra, C. Fité, Conversion of 1-hexanol to din-hexyl ether on acidic catalysts, Applied Catalysis A: General 374 (2010) 41-47

[24] R. Bringué, J. Tejero, M. Iborra, C. Fité, J.F. Izquierdo, F. Cunill, Study of the chemical equilibrium of the liquid-phase dehydration of 1-hexanol to dihexyl ether, J. Chem. Eng. Data 53 (2008) 2854-2860

[25] R. Bringué, E. Ramírez, M. Iborra, J. Tejero, F. Cunill, Influence of acid ionexchange resins morphology in a swollen state on the synthesis of ethyl octyl ether from ethanol and 1-octanol, Journal of Catalysis 304 (2013) 7-21.

[26] R. Bringué, M. Iborra, J. Tejero, J.F. Izquierdo, F. Cunill, C. Fité, V.J. Cruz, Thermally stable ion-exchange resins as catalysts for the liquid-phase dehydration of 1pentanol to di-n-pentyl ether (DNPE), Journal of Catalysis 244 (2006) 33-42

[27] R. Wittig, J. Lohmann, J. Gmehling, Vapor-liquid equilibria by UNIFAC group contribution. 6. Revision and extension, Industrial and Engineering Chemistry Research 42 (2003) 183-188 
[28] R. Bringué, E. Ramírez, C. Fité, M. Iborra, J. Tejero, Kinetics of 1-pentanol etherification without water removal, Industrial and Engineering Chemistry Research 50 (2011) 7911-7919

[29] A.W. Adamson, Physical Chemistry of Surfaces, fifth ed., Wiley, New York, 1990 